DOI: https://doi.org/10.15688/jvolsu4.2020.1.16

UDC 94(47)

Submitted: 24.11.2019

LBC 63.3(2)4

Accepted: 27.12 .2019

\title{
ON THE ISSUE OF THE BAPTISM OF PRINCESS OLGA
}

\author{
Alexey V. Petrov \\ Saint Petersburg State University, Saint Petersburg, Russian Federeation; \\ Saint Petersburg Theological Academy, Saint Petersburg, Russian Federeation
}

\begin{abstract}
Introduction. More than once researchers will address this issue and related subjects. Where, how and why did Princess Olga receive holy baptism? When and in what capacity did she travel to Constantinople? What was the meaning of Olga's baptism for Rus? Was the blessed princess the ruler of a pagan state? The author proposes to share his thoughts on this subject in this article. Methods. The method of considering this issue ultimately comes down to finding the best option for reconciling conflicting testimony of sources, taking into account extensive historiography, but also in the context of a particular historiographic and theoretical paradigm. Analysis. The opinion about the official nature of Olga's trip to Constantinople as the full-fledged ruler of the Russian land can be successfully opposed by the opinion that the visit of the princess to the capital of the empire is a private event in the life of the widow of the Russian prince. Doubts were justified that she could be equal in status to her late husband and fully take control of his princely duties and government powers. Most likely, her political position was ambivalent. It is difficult to deny the baptism of Igor's widow in Constantinople, because all the sources talking about him, not coinciding in the dating of this event, nevertheless, unanimously localize him there. Results. Christianity, adopted by Princess Olga in 957 in Constantinople during an unofficial trip there as part of a trade caravan, from the very act of baptism to the end of the princess's life, remained only her personal affair. After baptism, Olga completely refused to participate in government activities. The latter circumstance allows emphasizing that aspect of her Christian feat that researchers did not pay attention to: conscious self-removal from power (even symbolic) in pagan society in order to follow Christian commandments and adhere to Christian values.

Key words: princess Olga, baptism of princess Olga, Baptism of Rus, first Russian Christians, first Rurikovichi, people and power in Ancient Russia, paganism and Christianity in Ancient Rus, Rus and Byzantium in the $10^{\text {th }}$ century.

Citation. Petrov A.V. On the Issue of the Baptism of Princess Olga. Vestnik Volgogradskogo gosudarstvennogo universiteta. Seriya 4. Istoriya. Regionovedenie. Mezhdunarodnye otnosheniya [Science Journal of Volgograd State University. History. Area Studies. International Relations], 2020, vol. 25, no. 1, pp. 200-207. (in Russian). DOI: https://doi.org/10.15688/jvolsu4.2020.1.16
\end{abstract}

\section{К ВОПРОСУ О КРЕЩЕНИИ КНЯГИНИ ОЛЬГИ}

\section{Алексей Владимирович Петров}

Санкт-Петербургский государственный университет, г. Санкт-Петербург, Российская Федерация; Санкт-Петербургская Духовная Академия, г. Санкт-Петербург, Российская Федерация

Аннотация. Введение. Еще не однажды к данному вопросу и связанным с ним сюжетам будут обращаться исследователи. Где, как и почему княгиня Ольга приняла святое крещение? Когда и в каком качестве 
она ездила в Константинополь? Каково было для Руси значение крещения Ольги? Была ли блаженная княгиня правительницей языческого государства? Автор предполагает поделиться своими соображениями на сей счет в данной статье. Meтодbl. Метод рассмотрения данного вопроса в конечном счете сводится к поиску оптимального варианта согласования противоречивых показаний источников с учетом обширной историографии, но и в контексте определенной историографической и теоретической парадигмы. Анализ. Мнению об официальном характере поездки Ольги в Царьград как полноправной правительницы Русской земли может быть с успехом противопоставлено мнение, что визит княгини в столицу империи - частное событие из жизни вдовы русского князя. Оправданы сомнения в том, что она могла быть равновеликой по статусу своему покойному мужу и в полной мере взять в свои руки его княжеские обязанности и правительственные полномочия. Скорее всего, ее, именно политическое, положение было двойственным. Отрицать факт крещения вдовы Игоря в Константинополе сложно, ибо все, говорящие о нем источники, не совпадая в датировке этого события, тем не менее, единодушно локализуют его именно там. Результатыл. Христианство, принятое княгиней Ольгой в 957 г. в Константинополе во время неофициальной поездки туда в составе торгового каравана, от самого акта крещения и до конца жизни княгини оставалось только ее личным делом. После крещения Ольга и вовсе отказалась от участия в правительственной деятельности. Последнее обстоятельство позволяет акцентировать тот аспект ее христианского подвига, на который не обращали внимания исследователи: сознательное самоустранение от власти (даже символической) в языческом обществе ради следования христианским заповедям и приверженности христианским ценностям.

Ключевые слова: княгиня Ольга, крещение княгини Ольги, Крещение Руси, первые русские христиане, первые Рюриковичи, народ и власть в Древней Руси, язычество и христианство в Древней Руси, Русь и Византия в Х веке.

Цитирование. Петров А. В. К вопросу о крещении княгини Ольги // Вестник Волгоградского государственного университета. Серия 4, История. Регионоведение. Международные отношения. - 2020. - Т. 25 , № 1. - C. 200-207. -DOI: https://doi.org/10.15688/jvolsu4.2020.1.16

Введение. Вопрос о крещении киевской княгини Х столетия Ольги широко обсуждался как в отечественной, так и зарубежной исторической литературе. Дискуссия далека от завершения и ныне. В основном это событие локализовали в Киеве или Константинополе, датируя 957 г., периодом после 957 и более ранним временем. Одни авторы считали принятие христианства личным делом вдовы Игоря, другие видели здесь первый шаг к крещению всей Руси [3, с. 222-237; 17, с. 262-270].

Самым интеллектуально богатым, на мой взгляд, моментом обсуждения данного вопроса стали серия статей Г.Г. Литаврина и аргументированный ответ на них А.В. Назаренко [5-12]. Крупнейшие российские историки ударили друг друга копьями, как Пересвет и Челубей, и оставили нас разбираться с дальнейшим...

50 на 50 - либо 957, либо 946, как годы посещения Ольгой Царьграда. Я склоняюсь к 957 г. на том основании, что после убийства Игоря на стабилизацию положения в России («'Р Русскую землю тогдашние греческие интеллектуалы [2, с. 45; и др.], определенно потребовалось бы время.
Отсутствие единства среди исследователей по вопросу о крещении княгини Ольги обусловлено крайним немногословием и противоречивостью данных источников. Из обстоятельств, в той или иной мере имеющих к нему отношение, бесспорно только то, что в середине X в. мать Святослава находилась в столице ромеев, где была дважды принята императором Константином VII Багрянородным, о чем сохранился рассказ в его трактате «О церемониях византийского двора» [19, lib. II, cap. 15, p. 594 598]. Этот рассказ неоднократно переводился на русский язык [1, с. 99-102; 4, с. 360-364].

Метод рассмотрения данного вопроса в конечном счете сводится к поиску оптимального варианта согласования противоречивых показаний источников с учетом обширной историографии, но и в контексте определенной историографической и теоретической парадигмы. Ни о каких феодальном обществе и феодальном государстве, требующих масштабного изменения идеологии, на Руси IX-X вв. речи быть не может [18, с. 8-33 и сл.]. Равно как не может быть речи о сложно стратифицируемом социуме, каковой иногда сейчас изображают, подчиняясь советской историографической инерции. И другой методологичес- 


\section{ВЛАСТЬ И ОБЩЕСТВО}

кой предпосылкой к рассмотрению избранного вопроса послужило уяснение того, как именно взаимодействовало христианство с язычеством. Силава язычества с христианством в средневековой Руси не было. Русская древность - время сосуществования разорванных культурных пластов, время раздвоения общественного сознания и, вместе с тем, время накоплявшихся успехов христианизации в религиозно-моральном и политическом аспектах. Русское средневековье - и пора противоборства с язычеством, и история постепенного нравственного торжества христианства [15]. Вот в каком историческом и психологическом контексте принимала христианство св. княгиня Ольга. И это, безусловно, повышает значение ее Личности.

Анализ. Для чего приезжала Ольга в Царьград?

В.А. Пархоменко, М.Д. Приселков, М.В. Левченко, А.Н. Сахаров и др. [17, с. $262-$ $270]$ полагали, что поездка княгини Ольги носила официальный характер, ибо, по их мнению, она возглавляла посольство, прибывшее в Константинополь для дипломатических переговоров. Однако мы не можем настаивать на данном тезисе. Единственный весомый довод в его пользу - строки Повести временных лет, где сказано, что Ольга обещала византийскому басилевсу прислать рабов, воска, мехов и воинов на помощь. Но этих строк, все же, недостаточно, чтобы предположить наличие каких-либо дипломатических переговоров. Даже если подобные обещания действительно имели место, то княгиня могла дать их, вовсе и не будучи вполне официальным лицом, тем более что они так и остались невыполненными. К тому же, не исключено, что нарушение обязательств, якобы принятых вдовой Игоря в беседе с императором, продолжает ту же самую летописную линию «переклюкивания» греческого царя, которая началась с хитроумного уклонения от его сватовства. Что же касается предложения византийскому монарху постоять в Киеве «на Почайне» так же, как она стояла «в Суду», то здесь, вероятнее всего, нашло отражение традиционное недовольство русских процедурой долгого и стеснительного ожидания, раздражавшего их всякий раз по прибытии в Константинополь [16, с. 30].
Мнению об официальном характере поездки Ольги в Царьград, как полноправной правительницы Русской земли, на мой взгляд, может быть с успехом противопоставлено наблюдение, что визит княгини в столицу империи - частное событие из жизни вдовы русского князя. Позднейшие летописцы-монахи окружили созданный ими образ матери Святослава ореолом величия и мудрости именно потому, что она находилась в ряду первых русских христиан, крестившись намного раньше других представителей княжеского рода.

Оправданы сомнения в том, что она могла быть равновеликой по статусу своему покойному мужу и в полной мере взять в свои руки его княжеские обязанности и правительственные полномочия. Скорее всего, ее, именно политическое, положение было двойственным. Тогдашняя Русь переживала последнюю стадию распада племенного строя - рушились и смешивались, форматировались по административно-территориальным округам, «волостям», под влиянием различных факторов, описанные Константином Багрянородным «Славинии», или «племенные княжения» Повести временных лет $[2$, с. 45,$317 ; 16$, с. 10 ; и др.]. Знатные женщины европейских «варварских обществ» раннего средневековья славянских и германских - едва ли могли обладать официальной возможностью править, быть политическими (потестарными, если угодно) лидерами социумов, равнозначными в этом отношении своим мужьям. Особенности и свойства эпохи «славного варварства», «военной демократии», «позднейшей стадии племенных союзов», когда они интегрировались в «суперсоюзы», «чифдомы», предполагали, что выполнение основных княжеских функций являлось исключительно мужским делом! При малолетнем Святославе, в период, когда Русь не имела настоящего князя, княгиня Ольга была необходимым символом, олицетворением княжеской власти, номинальным правителем России.

От внимательного читателя Повести временных лет не скроется, что в это время, которое, - и это должно быть особенно знаменательным, - описывается в летописи под заглавием: «Начало княженья Святослава, сына Игорева», рядом с княгиней, чтобы она не предпринимала, неизменно стоят две мо- 
гущественные фигуры: Асмуд и Свенельд. От имени последнего, равно как и от имени Святослава, даже заключен договор с греками 971 года [16, с. 27-28, 34]. Если при воинственном и могущественном князе-«пардусе» этот воевода занимал столь высокое положение, то каково же было его значение, когда Святослав еще «бе детеск»?! Мне представляется, что именно Свенельд являлся главной фигурой в политической жизни Руси от смерти Игоря и до возмужания Святослава. Таким образом, говоря о «регентстве» при малолетнем княжиче, нужно учитывать, что их (регентов) было трое: помимо Ольги - Асмуд и Свенельд, при явном первенстве последнего.

Ольга была символом княжеской власти в России, но приехала она в 957 г. в Царьград не в качестве главы дипломатической миссии, а как знатная паломница, воспользовавшаяся для своего дальнего путешествия обычным киевским торговым караваном, чем и объясняется отмеченное Константином Багрянородным большое количество купцов в ее окружении. Княгиня стремилась своими глазами увидеть Второй Рим, слава которого давно уже достигла лесного Приднепровья, и принять здесь христианство.

У нас нет данных, чтобы говорить о том, что именно побудило Ольгу к крещению. Но я с легкостью предположу, что тут сыграли свою роль и свойства ее личности, и то, что «душа человеческая по природе своей христианка».

Отрицать факт крещения вдовы Игоря в столице ромеев сложно, ибо все, говорящие о нем источники, не совпадая в датировке этого события, тем не менее, единодушно локализуют его именно там. Поскольку княгиня Ольга была в Константинополе, скорее всего, именно в 957 г., а удвоение ее поездки на берега Босфора, как уже указывалось в литературе $[17$, с. 285], искусственно, то следует заключить, что мать Святослава крестилась именно тогда, во время своего цареградского визита в 957 году.

Противники такой точки зрения, в том числе и такие известные специалисты, как Г.А. Острогорский и Ж.-П. Ариньон, ссылаются при своих рассуждениях главным образом на молчание о факте крещения трактата Константина Багрянородного «О церемониях византийского двора». По их мнению, император обязательно нашел бы возможность сообщить о принятии христианства его гостьей, если бы оно действительно имело место в 957 г. в Царьграде. «Если представить себе, пишет, например, Г.А. Острогорский, - каким событием для византийской столицы и для самой императорской семьи явилось бы крещение киевской княгини во время ее пребывания в Константинополе, если принять во внимание, к тому же, что крещение как таковое идеологически значило для каждого византийца, то умолчание о нем, мне кажется, может быть объяснено единственно тем, что Ольга крестилась не в Константинополе...» [13, c. 1463]. На мой взгляд, такое решительное утверждение спорно.

В.А. Пархоменко, М.В. Левченко, Г.А. Острогорскому, Ж.-П. Ариньону и др. удалось доказать лишь возможность, а отнюдь не обязательность наличия в Книге о церемониях упоминания о крещении Ольги. Если смягчить излишнюю категоричность суждений тех историков, которые, впадая в противоположную крайность, считали, что Константин Багрянородный совсем не мог упомянуть о факте крещения (так как, по их мнению, писал всего лишь практическое руководство по придворному церемониалу, а не исторический трактат), то с ними можно согласиться в том смысле, что в центре внимания императора было не все целиком пребывание киевской княгини в Византии, а только ее визиты в царский дворец. Константин Багрянородный не поведал о целях, которые привели Ольгу в Царьград, не сообщил, где она жила и чем занималась здесь, помимо двух приемных дней. Все это делает вполне приемлемой мысль, что наряду с прочими недомолвками, царственный писатель мог смолчать и о ее крещении, состоявшемся в неприемное время (скорее всего, и после приемов) за стенами императорских чертогов, тем более, отмеченные Г.А. Острогорским [13] сбивчивость, непоследовательность и пестрота Книги о церемониях очевидно должны были способствовать этому.

К тому же молчание императора по интересующему нас поводу было в значительной степени обусловлено еще и тем, что крещение вдовы Игоря во время ее частного ви- 


\section{ВЛАСТЬ И ОБЩЕСТВО}

зита в Константинополь не могло оказаться ничем иным, как тоже только частным актом, не претендующим ни на какое политическое значение.

Другое дело, что, вернувшись в Киев, Ольга, по свидетельству хроники Продолжателя Регинона Прюмского, сделала попытку пригласить на Русь христианского епископа и священников, чем явно превысила свои полномочия. Как и следовало ожидать, эта попытка завершилась полным провалом, ибо, судя по тому же источнику, приглашенных проповедников с шумом выдворили из страны. И случилось так из-за того, что вдова Игоря не пользовалась всеми правами настоящего князя (мужчины, военного предводителя), что сама княжеская власть тогда, в соответствии с переживаемой стадией общественного развития, была обязана считаться как с народным собранием-вечем, так и с советом старейшин (летописных «старцев градских») [18, с. 8-63; и др.], а также из-за того, что в рассматриваемое время Держава Рюриковичей все еще оставалась главным образом языческой.

Христианство стало проникать к русским славянам с начала IX века. В середине этого столетия среди русских уже существовали купцы-христиане, которым в далеком Багдаде переводчиками служили местные славянские невольники. В 60-е гг. IX в. зафиксировано бытование Евангелия и Псалтыри, написанных «руськими письменами», и, самое главное, состоялось первое массовое крещение Руси - «Фотиево крещение». Потом, в связи с появлением в Приднепровье Олега во главе новой волны переселенцев с севера («и беша у него варязи и словени и прочи, прозвашася русью») [16, с. 14], по всей видимости, наступил период «языческой реакции». Процесс проникновения христианства на Русь, несмотря на его внушительные успехи, воплощенные в «Фотиевом крещении», был прерван и должен был начаться заново. При Игоре в Киеве существовала христианская община, которую отдельно приводили к присяге при заключении очередного договора с Империей [16, с. 26, 163].

Но и при Ольге язычество продолжало доминировать на Руси. «Людье мои погани и сынъ мой, дабы мя Богъ съблюлъ от всякого зла», - говорила, согласно летописи, святая княгиня [16, с. 30]. Прав был В.А. Пархоменко, когда отметил, что «в эту пору христианство на Русь еще лишь начало проникать - в результате завязавшихся торговых связей с соседями - и существовало здесь еще по преимуществу среди пришлого элемента, - главное же ядро Руси прочно и безмятежно пребывало пока в своей отеческой вере» [14, c. 432]. Киевские язычники середины X столетия могли сравнительно спокойно жить бок о бок с христианами, демонстрируя тем самым пример религиозной терпимости, но всякая попытка навязать новую веру неминуемо встретила бы оппозицию в лице юного князя Святослава, его дружины, подавляющего большинства народа. Условия, которые сделают возможным официальное принятие христианства на языческой Руси в конце века, при Ольге еще не сложились. В частности, печенежская опасность еще не стала настолько серьезной, чтобы поставить перед русскими славянами вопрос о значительно более крепком внутреннем единстве ввиду надвигавшихся из степей кочевых орд.

Что же касается того, почему крещенная на берегах Босфора русская княгиня с просьбой о присылке священников обратилась на Запад, а не ко греческому императору, то и здесь можно найти объяснения. Во-первых, став христианкой частным образом во время своей поездки в Константинополь, Ольга не чувствовала себя чем-либо обязанной государству ромеев. Во-вторых, это вполне могло произойти еще и потому, что вдова Игоря, как и первые русские христиане из храма св. Ильи, плохо разбиралась в разнице Восточной и Западной Церквей, считая христианство единым и неделимым мировоззрением всего европейского мира. Да и официальный раздел между ними произошел много позже, в 1054 году. Тут можно сослаться на Повесть временных лет, в наиболее древних текстах которой «папежь римьский» - еще авторитетная и уважаемая фигура, недаром он вступился за правое дело и «похули тех, иже ропьщуть на книги словеньския» [16, с. 15].

Результаты. Итак, рассмотренные обстоятельства крещения княгини Ольги свидетельствуют о том, что христианство, принятое ею в 957 году в Константинополе во время неофициальной поездки туда в составе тор- 
гового каравана, от самого акта крещения и до конца жизни княгини оставалось только ее личным делом. Крещение Ольги - лишний довод в пользу мнения, что княгиня являлась лишь символом княжеской власти, а не действительным, сообразным условиям эпохи, правителем Руси, каковыми были ее муж и сын. Более того, есть все основания думать, что само решение принять христианство говорило о желании Ольги дистанцироваться от властной публичности в нехристианской стране, от эдакой publicity, противной постепенно овладевшим ею убеждениям. После своего приобщения к Истинной вере и после провала попытки пригласить на Русь священников по сути дела, ее единственной полностью самостоятельной политической акции, скорее показательной, чем рассчитанной на удачу, Ольга, похоже, и вовсе отказалась от участия в правительственной деятельности. Последнее обстоятельство позволяет акиентировать тот аспект ее христианского подвига, на который не обращали внимания исследователи: сознательное самоустранение от власти (даже символической) в языческом обществе ради следования христианским заповедям и приверженности христианским иченностям.

\section{СПИСОК ЛИТЕРАТУРЫ}

1. Голубинский, Е. Е. История Русской Церкви. T. І. Первая половина тома / Е. Е. Голубинский. - М. : Изд-во Патриаршего Крутицкого Подворья и Общество любителей церковной истории, 1997. - 968 с.

2. Константин Багрянородный. Об управлении империей / Константин Багрянородный. - М. : Наука, 1991. - 496 с.

3. Левченко, М. В. Очерки по истории руссковизантийских отношений / М. В. Левченко. - М. : Изд-во АН СССР, 1956. - 556 с.

4. Литаврин, Г. Г. Византия, Болгария, Древняя Русь (IX - начало ХІІ в.) / Г. Г. Литаврин. - СПб. : Алетейя, 2000.-416 c.

5. Литаврин, Г. Г. К вопросу об обстоятельствах, месте и времени крещения княгини Ольги / Г. Г. Литаврин // Древнейшие государства на территории СССР, 1985 г. - М. : Наука, 1986. - С. 43-57.

6. Литаврин, Г. Г. О датировке посольства княгини Ольги в Константинополь / Г. Г. Литаврин // История СССР. - 1981. - № 5. - С. 173-183.
7. Литаврин, Г. Г. Путешествие русской княгини Ольги в Константинополь: проблема источников / Г. Г. Литаврин // Византийский временник. М. : Наука, 1981.- Т. 42. - С. 35-48.

8. Литаврин, Г. Г. Реплика к статье [Назаренко А.В. Когда же княгиня Ольга...] / Г. Г. Литаврин // Византийский временник. - М. : Наука, 1989. T. 50. - С. 83-84.

9. Литаврин, Г. Г. Русско-византийские связи в середине Х в. / Г. Г. Литаврин // Вопросы истории. - 1986. - № 6. - С. 41-52.

10. Назаренко, А. В. Еще раз о дате поездки княгини Ольги в Константинополь / А. В. Назаренко // Образование Древнерусского государства: спорные проблемы : Чтения памяти чл.-кор. АН СССР В. Т. Пашуто, Москва 13-15 апр. 1992 г. М. : ИРИ, 1992. - С. 47-49.

11. Назаренко, А. В. Еще раз о дате поездки княгини Ольги в Константинополь: источниковедческие заметки / А. В. Назаренко // Древнейшие государства Восточной Европы, 1992-1993 гг. - М. : Наука, 1995. - С. 154-168.

12. Назаренко, А. В. Когда же княгиня Ольга ездила в Константинополь? / А. В. Назаренко // Византийский временник. - М. : Наука, 1989. - Т. 50.C. $66-83$.

13. Острогорский, Г. А. Византия и киевская княгиня Ольга / Г. А. Острогорский // Тo Honor of Roman Jakobson. Essays on the occasion of his seventieth Birthday. - Paris : La Haye, 1967. - Vol. 2. C. $1458-1473$.

14. Пархоменко, В. А. О крещении св. княгини Ольги / В. А. Пархоменко // Вера и разум. - Харьков, 1911. - № X, кн. 2. - С. 429-446.

15. Петров, А. В. Святой Равноапостольный князь Владимир и Крещение Руси (к чествованию памяти в связи с 1000-летием преставления) / А. В. Петров // Христианское чтение. - СПб., 2015. - № 6. - С. 10-21.

16. Повесть временных лет / подготовка текста, перевод, статьи и комментарии Д. С. Лихачева ; под ред. В. П. Адриановой-Перетц. - Изд. 2-е. - СПб. : Наука, 1996. - 668 с.

17. Сахаров, А. Н. Дипломатия Древней Руси (IX - первая половина Х в.) / А. Н. Сахаров. - М. : Мысль, 1980. - 358 с.

18. Фроянов, И. Я. Киевская Русь. Очерки социально-политической истории / И. Я. Фроянов. Л. : Изд-во ЛГУ, 1980. -256 с.

19. Constantinus Porphyrogenitus imperator. De cerimoniis aulae Byzantinae libri 2 / Rec. I. I. Reiske. Bonnae, 1829-1830. - Vol. 1-2. - Electronic text data. - Mode of access: https://archive.org/details/ bub_gb_OFpFAAAAYAAJ/page/n659. - Title from screen. 


\section{REFERENCES}

1. Golubinskiy E.E. Istoriya Russkoy Tserkvi. T. I. Pervaya polovina toma [History of the Russian Church. Vol. I. First Half of the Volume]. Moscow, Izdvo Patriarshego Krutitskogo Podvorya i Obshchestvo lyubiteley tserkovnoy istorii, $1997.968 \mathrm{p}$.

2. Konstantin Bagryanorodnyy. Ob upravlenii imperiey [About Empire Management]. Moscow, Nauka Publ., 1991. 496 p.

3. Levchenko M.V. Ocherki po istorii russkovizantiyskikh otnosheniy [Essays on the History of Russian-Byzantine Relations]. Moscow, Izdatelstvo AN SSSR, 1956. $556 \mathrm{p}$.

4. Litavrin G.G. Vizantiya, Bolgariya, Drevnyaya Rus (IX-nachalo XIIv.) [Byzantium, Bulgaria, Ancient Russia ( $9^{\text {th }}-$ Early $12^{\text {th }}$ Century.)]. Saint Petersburg, Aleteya Publ., 2000. 416 p.

5. Litavrin G.G. K voprosu ob obstoyatelstvakh, meste i vremeni kreshcheniya knyagini Olgi [On the Circumstances, Place and Time of the Baptism of Princess Olga]. Drevneyshie gosudarstva na territorii SSSR, $1985 \mathrm{~g}$. [The Oldest States in the Territory of the USSR, 1985]. Moscow, Nauka Publ., 1986, pp. 43-57.

6. Litavrin G.G. O datirovke posolstva knyagini Olgi v Konstantinopol [About the Dating of the Embassy of Princess Olga in Constantinople]. Istoriya SSSR, 1981, no. 5, pp. 173-183.

7. Litavrin G.G. Puteshestvie russkoy knyagini Olgi v Konstantinopol: problema istochnikov [Journey of Russian Princess Olga to Constantinople. Problem of Sources]. Vizantiyskiy vremennik [Byzantina Xronika]. Moscow, Nauka Publ., 1981, vol. 42, pp. 35-48.

8. Litavrin G.G. Replika k statye [NazarenkoA.V. Kogda zhe knyaginya Olga...] [Remark to the Article [Nazarenko A.V. When Princess Olga...]]. Vizantiyskiy vremennik [Byzantina Xronika]. Moscow, Nauka Publ., 1989, vol. 50, pp. 83-84.

9. Litavrin G.G. Russko-vizantiyskie svyazi v seredine X v. [Russian-Byzantine Relations in the Mid $10^{\text {th }}$ Century]. Voprosy istorii, 1986, no. 6, pp. 41-52.

10. Nazarenko A.V. Eshche raz o date poezdki knyagini Olgi v Konstantinopol [Once Again About the Date of the Trip of Princess Olga to Constantinople]. Obrazovanie Drevnerusskogo gosudarstva: spornye problemy: Chteniya pamyati chl.-korr. AN SSSR V.T. Pashuto, Moskva 13-15 apr.
1992 g. [Formation of the Old Russian State: Controversial Issues. Readings in Memory of Corresponding Member of the USSR Academy of Sciences V.T. Pashuto, Moscow, April 13-15, 1992]. Moscow, IRI Publ., 1992, pp. 47-49.

11. Nazarenko A.V. Eshche raz o date poezdki knyagini Olgi v Konstantinopol: istochnikovedcheskie zametki [Once Again About the Date of the Trip of Princess Olga to Constantinople. Source Study Notes]. Drevneyshie gosudarstva Vostochnoy Evropy, 19921993 gg. [Ancient States of Eastern Europe, 19921993]. Moscow, 1995, pp. 154-168.

12. Nazarenko A.V. Kogda zhe knyaginya Olga ezdila v Konstantinopol? [When did Princess Olga Go to Constantinople?]. Vizantiyskiy vremennik [Byzantina Xronika]. Moscow, Nauka Publ., 1989, vol. 50, pp. 66-83.

13. Ostrogorskiy G.A. Vizantiya i kievskaya knyaginya Olga [Byzantium and Kiev Princess Olga]. To Honor of Roman Jakobson. Essays on the Occasion of His Seventieth Birthday. Paris, La Haye, 1967, vol. 2, pp. 1458-1473.

14. Parkhomenko V.A. O kreshchenii sv. knyagini Olgi [About the Baptism of St. Olga]. Vera i razum [Faith and Reason]. Kharkiv, 1911, no. X, book 2, pp. 429-446.

15. Petrov A.V. Svyatoy Ravnoapostolnyy knyaz Vladimir i Kreshchenie Rusi (k chestvovaniyu pamyati v svyazi s 1000-letiem prestavleniya) [Holy Equal-tothe-Apostles Prince Vladimir and the Baptism of Russia (To the Celebration of Memory in Connection with the $1000^{\text {th }}$ Anniversary of the Repose)]. Khristianskoe chtenie [Christian Reading]. Saint Petersburg, 2015, no. 6, pp. 10-21.

16. Likhachev D.S., Adrianova-Peretts V.P., eds. Povest vremennykh let [Tale of Bygone Years]. Saint Petersburg, Nauka Publ., 1996. 668 p.

17. Sakharov A.N. Diplomatiya Drevney Rusi (IX-pervaya polovina $X$ v.) [Diplomacy of Ancient Russia ( $9^{\text {th }}-$ First Half of the $10^{\text {th }}$ Century) $]$. Moscow, Mysl Publ., 1980. 358 p.

18. Froyanov I.Ya. Kievskaya Rus. Ocherki sotsialno-politicheskoy istorii [Kievan Rus. Essays on Socio-Political History]. Leningrad, Izd-vo LGU, 1980. $256 \mathrm{p}$.

19. Constantinus Porphyrogenitus imperator. De cerimoniis aulae Byzantinae libri 2. Bonnae, 18291830, vol. 1-2. URL: https://archive.org/details/ bub_gb_OFpFAAAAYAAJ/page/n659. 


\section{Information About the Author}

Alexey V. Petrov, Doctor of Sciences (History), Associate Professor, Professor, Department of Russian History from Ancient Times to the $20^{\text {th }}$ Century, Saint Petersburg State University, Universitetskaya Emb., 7-9, 199034 Saint Petersburg, Russian Federation; Professor, Department of Church History, Saint Petersburg Theological Academy, Obvodnogo Kanala Emb., 17, 193167 Saint Petersburg, Russian Federation, a.v.petrov@spbu.ru, a.v.petrov@mail.ru,https://orcid.org/0000-0001-5479-8087

\section{Информация об авторе}

Алексей Владимирович Петров, доктор исторических наук, доцент, профессор кафедры истории России с древнейших времен до XX века, Санкт-Петербургский государственный университет, Университетская наб., 7-9, 199034 г. Санкт-Петербург, Российская Федерация; профессор кафедры церковной истории, Санкт-Петербургская Духовная Академия, наб. Обводного канала, 17, 193167 г. Санкт-Петербург, Российская Федерация, a.v.petrov@spbu.ru, a.v.petrov@mail.ru, https://orcid.org/0000-0001-5479-8087 